\title{
The Client Empowerment in Community Health Systems Scale: Development and validation in three countries
}

\author{
Tracy L McClair ${ }^{1}$, Pooja Sripad ${ }^{1}$, \\ Alain Casseus ${ }^{2}$, Sharif Hossain ${ }^{3}$, \\ Timothy Abuya ${ }^{4}$, Ann Gottert ${ }^{1}$ \\ ${ }^{1}$ Population Council, Washington, D.C., \\ USA \\ ${ }^{2} Z a n m i$ Lasante, Mirebalais, Haiti \\ ${ }^{3}$ Population Council, Dhaka, Bangladesh \\ ${ }^{4}$ Population Council, Nairobi, Kenya
}

\begin{abstract}
Background Effectively measuring client empowerment is critical for monitoring and supporting empowerment through interventions, including via community health workers (CHWs) on the front line. Yet a comprehensive measure capturing the multidimensional aspects of client empowerment is not currently available. We aimed to develop and validate the Client Empowerment in Community Health Systems (CE-CHS) Scale in three countries.
\end{abstract}

Methods We used data from cross-sectional surveys from 2019-2020 with clients of CHWs in Bangladesh $(n=1384)$, Haiti $(n=616)$, and Kenya $(n=306)$. Nineteen candidate CE-CHS Scale items were adapted from existing health empowerment and sociopolitical control scales. Items spanned three hypothesized sub-domains: personal agency around health (eg, "I feel in control of my health"), agency in sharing health information with others (eg, "I feel confident sharing health information with my family/friends"), and empowerment in community health systems (eg, "Most facility/managers would listen to any concerns I raise"). Face and content validity of items were assessed via two focus group discussions in Haiti. For each country, we conducted split-sample exploratory/confirmatory factor analyses (EFA/ CFA) and assessed internal consistency reliability. We assessed convergent validity by comparing final full-scale and sub-dimension scores to theoretically related variables.

Results All participants in Bangladesh and Kenya were female, as were 85\% in Haiti. Mean age in Bangladesh and Kenya was around 25 years; 40 in Haiti. EFA/CFA resulted in a final 16-item CE-CHS Scale representing the three hypothesized sub-scales. Three items were dropped in EFA due to poor performance. CFA fit statistics were good for the full-scale and each sub-scale. The mean CE-CHS score (range 1 to 4) was 2.4 in Bangladesh, 2.8 in Haiti, and 3.0 in Kenya. Cronbach's alpha and ordinal theta of the full and subscales were greater than 0.7 . Increased empowerment was associated with increased trust in CHWs, influence of CHWs on empowerment, satisfaction with CHW services, number of CHW interactions, civic engagement, and education, with slight variations in magnitude and significance by country.

Conclusions Findings suggest that the 16-item CE-CHS Scale is valid and reliable. This scale can be used to assess levels and determinants of, and changes in, client empowerment in future implementation research and monitoring of community health systems.

\section{Correspondence to:}

Tracy L. McClair, MSPH

4301 Connecticut Avenue NW, Suite 280

Washington, DC 20008

USA

tmcclair@popcouncil.org 
Empowered community members are more likely to engage in behaviors that promote their own health and that of their families and communities [1]. Client empowerment in a community health system, an extension of the broader primary health care system, can be influenced by community health workers (CHWs). Agarwal et al. define client empowerment as "community members' agency - awareness of and access to - community health services as well as the participation or engagement of communities in shaping and maintaining community health services (including CHW programs) [2]."

Client empowerment is both a process that can contribute to improved health outcomes, and can be conceptualized as an important outcome itself [3]. Previous research has shown that individuals can better achieve their own health goals if they are empowered to engage with others in their community who are in similar circumstances as them [1]. For example, participatory learning exercises in women's groups, often facilitated by CHWs, have been shown to be associated with maternity care seeking and reductions in neonatal and maternal mortality [4-7].

Empowerment is a multidimensional and highly contextual concept that can occur at multiple levels of the socioecological model, which posits that the entire ecological system, composed of four levels - microsystem, mesosystem, exosystem, and macrosystem - is necessary for understanding human development [8]. In the context of community health systems, at the individual (microsystem) level, clients can be empowered to have personal agency around their own and/or their family's health. At the interpersonal (mesosystem) level, clients can be empowered to share health information with their friends and family. At the community (exosystem) level, clients can engage with community health systems at large and exert sociopolitical control - the belief of one's skills and capabilities in the context of social and political systems such as community health systems [9]. Client empowerment can also depend on societal values inherent in countries' unique sociocultural contexts (macrosystem).

CHWs are essential to health systems since they provide a basic level of primary care conveniently within the community while linking community members with health institutions [10]. CHWs are uniquely positioned to support universal health coverage goals by reaching underserved populations who may have limited access to health services with health promotion and preventative services, for example, in the areas of family planning (FP), maternal and child health, nutrition, HIV, malaria, and tuberculosis [11]. CHWs also play an important role in meeting clients' psychosocial needs by being accessible in their communities, serving as an advocate for health and well-being, and listening and helping address clients' health concerns. Given the role of CHWs in their communities, they can support client empowerment in the context of community health systems.

Empowerment of community members has been recognized as an essential component of community health systems. The first two of ten principles to institutionalizing community health outlined by Pfaffmann Zumbruni et al. center around empowerment: empower communities to build community health systems and hold them accountable [12]. However, the authors are not aware of a previously validated, comprehensive empowerment scale that captures the multi-level aspects of client empowerment in the context of community health systems, which could also be important for assessing and improving CHW performance. Notably, many existing empowerment scales largely focuses on empowerment at the individual level, such as psychological empowerment, while less attention is paid to empowerment at the interpersonal and community levels, which are necessary for the sustainability of positive health behaviors and outcomes [13-17].

Under the Frontline Health project - a three-and-a-half year initiative led by Population Council to harmonize CHW performance metrics and promote the use of evidence in CHW programming - this study was conducted to develop and validate the Client Empowerment in Community Health Systems Scale (CE-CHS) in three countries [18].

\section{METHODS}

\section{Study design and setting}

We employed a scale development approach by generating items through a review of the literature on health agency and sociopolitical empowerment scales and domains, conducting qualitative research around the conceptualization of client empowerment in community health systems, and engaging in expert consultation to assess face validity [19].

The resulting nineteen candidate scale items were embedded in cross-sectional surveys of clients of CHWs. Surveys were part of larger studies in Bangladesh, Haiti, and Kenya that evaluated country-specific implemen- 
tation research questions around CHW programs [18]. The health topic areas of focus for these studies were different in the three settings (FP in Bangladesh, general health in Haiti, and antenatal/postnatal care in Kenya) corresponding to the varied topics of CHW's work globally.

\section{Study participants and sampling}

Our sample included clients who had recently interacted with a CHW. In Bangladesh, this included women ages 15 to 35 years who were non-users of any FP method or who discontinued methods in the last 3 months and who had interacted with Family Welfare Assistants (FWAs) or Family Welfare Visitors (FWVs) in the last six months in 12 unions in Keraniganj upazila (sub-district), Dhaka. In Haiti, the sample included women and men ages 15 and older who interacted with Agents de Santé Communautaire Polyvalent (ASCPs) in the last six months on any health issue in three communes in Artibonite and Centre departments. In Kenya, the sample included pregnant women in the second or third trimester and mothers of babies 0-59 days ages 16 and older who saw a community health volunteer (CHV) for antenatal or postnatal counseling in the last three months in four sub-counties in Bungoma and Kilifi counties. Detailed descriptions of sampling strategies for Bangladesh and Kenya are described elsewhere [20,21]. In Haiti, a simple random sample approach of the combined ASCP registry and digital database was used to sample clients recruited by Zanmi Lasante's team and a community guide.

\section{Survey Procedures}

All data collectors were extensively trained and obtained informed consent from all participants by signature or thumb print for those with limited literacy. Using relevant languages (Bengali in Bangladesh, Creole in Haiti, and Kiswahili in Kenya), data collectors administered the survey in the clients' home in Bangladesh and Haiti and in health facilities in Kenya. Surveys were paper-based in Bangladesh and tablet-based using Open Data Kit software in Haiti and Kenya. Data from all three countries were collected between July 2019 and January 2020.

Ethical approval was obtained from the Population Council Institutional Review Board in New York, USA (p874, p879, and p876), as well as the Bangladesh Medical Research Council (20608052019), the Zanmi Lasante Institutional Review Board in Haiti (ZLIRB2732019), and AMREF Health Africa Ethics and Social Review Committee in Kenya (p573).

\section{Scale development}

A pool of testable empowerment scale items was adapted from previously published scales as well as qualitative research conducted in Haiti. We undertook an iterative process by drafting questions with local study team members and experts in scale development and community health [2,22-24]. We drew on Bann et al.'s empowerment scale to develop the personal agency sub-scale [25]. Findings from the Population Council studies under the Ending Eclampsia project on the health and well-being benefits of community health groups informed the development of the information sharing sub-scale [26]. We drew from Peterson et al.'s sociopolitical control scale to develop the engagement with community health systems sub-scale [9].

Nineteen testable items fell broadly under three hypothesized domains corresponding to the individual, interpersonal, and community levels of the socioecological model: personal agency around health, agency in sharing health information with others, and engagement in community health systems. The scale was introduced by the statement "Now I will read a series of statements. Please let me know how much you agree or disagree with each of these statements." Respondents were then asked whether they 'strongly disagree', 'disagree', 'agree', or 'strongly agree' with each statement.

All scale items were translated into Bengali, Creole, or Kiswahili, and checked for meaning and comprehension by the study team, and items were pretested to refine item wording. To assess face and content validity of the preliminary set of items, two focus group discussions were held in Haiti with men $(n=6)$ and women $(n=7)$ who met survey eligibility criteria. They were selected purposively by Zanmi Lasante staff and CHW supervisors. After participants self-administered the set of items, participants re-reviewed items together one by one, and for each discussed: "What does this statement mean to you?', 'Is this a useful/relevant statement?', 'Does the language used make sense?', 'How can it be changed?', 'Should we keep or remove it?' There were no issues with comprehension of any of the scale items and all items translated well into the local language. Further, all items were deemed important. Based on this discussion, all 19 items were retained. 


\section{Data analysis}

All statistical analyses were performed using Stata v15 (StataCorp LLC, College Station TX, USA). We began by exploring response distributions for each item to confirm whether each had adequate variation (eg, did not have $>90 \%$ in one category) to proceed to psychometric analyses.

Next, we randomly split each country's sample, designating half for exploratory factor analysis (EFA) and half for confirmatory factor analysis (CFA). All empowerment items were scored 1 to 4 , 'strongly disagree' to 'strongly agree.'

For EFAs, we conducted principal components analysis (PCA) to explore the number of factors underlying the set of items, by assessing the number of eigenvalues over 1.00, generating scree plots, and conducting parallel analysis to gauge the number of factors above the 'elbow' (for scree plot) or line (for parallel analysis) [19]. Items were retained for testing in the CFA model if they had low uniqueness $(<0.5)$, adequate factor loadings $(>0.3)$, and the item was conceptually necessary based on face and content validity.

To test the emergent factor structure from the EFA, we conducted CFA using the CFA samples for each country. We retained items with statistically significant factor loadings $(P<0.05)$. We then assessed CFA model fit using common cutoff criteria including the root mean square error of approximation (RMSEA) of $<0.10$ (ideally $<0.05$ ), comparative fit index (CFI) and the Tucker-Lewis index (TLI) of $>0.90$ (ideally $>0.95$ ), and standardized root mean square residual (SRMR) of $<0.08$. We incorporated modification indices into CFA structural equation models to remove any correlated error terms due to similarly worded items, then reassessed model fit. We assessed model fit for each of the three sub-scales as well as the full (multidimensional) scale.

For the set of items resulting from the EFA and CFA, we assessed internal consistency reliability using Cronbach's alpha and ordinal theta; the latter assumes polychoric correlation and thus is more appropriate for items with limited response categories [27]. A cutoff of $\geq 0.7$ was used to determine adequate internal consistency.

Finally, we assessed convergent validity using the full sample for each country. We used multivariate linear regression to explore associations between the full-scale scores, as well as sub-scale scores, with theoretically correlated variables including trust in CHWs, perceived influence of CHWs on empowerment, satisfaction with $\mathrm{CHW}$ services, number of CHW visits, client's civic engagement, and education. Multivariate models were used to adjust for sociodemographic factors which could also contribute to differences in empowerment, including age, education, wealth, geographic area, parity (Bangladesh only), and sex (Haiti only). Analyses were also adjusted to account for clustering based on the sampling strategy in which CHWs listed potential study participants in their catchment areas in Bangladesh and Kenya. Table 1 includes measures for sociodemographic characteristics and variables used to assess convergent validity.

Table 1. Measures for sociodemographic characteristics and variables used to assess convergent validity

\begin{tabular}{|c|c|c|}
\hline VARIABLE NAME & VARIABLE TYPE & Definition \\
\hline \multicolumn{3}{|c|}{ Sociodemographic characteristics: } \\
\hline Age & Continuous & Respondents' age in years at time of survey \\
\hline Education* & Categorical & $\begin{array}{l}\text { Three categories including none, primary, secondary and above. In Haiti and Kenya, highest level of education/school- } \\
\text { ing attended; in Bangladesh, highest level of education completed }\end{array}$ \\
\hline Wealth & Categorical & $\begin{array}{l}\text { Wealth quintiles based on a wealth index tailored for each country with questions such as "What is the main material } \\
\text { of the floor of your dwelling?" with response options 'cement', 'earth/sand', 'other [28] }\end{array}$ \\
\hline Geographic area & Categorical & $\begin{array}{l}12 \text { unions in Bangladesh (Konda, Taghoria, Shuvadda, Sakta, Taranagar, Rohitpur, Kalatia, Hozratpur, Aganagar, Zingi- } \\
\text { ra, Basta, Kalindi); } 3 \text { communes in Haiti (Mirebalais, Verrettes, Petite Rivière de l'Artibonite); } 4 \text { sub-counties in Kenya } \\
\text { (Kaloleni, Torgaren, Webuye West, Kilifi North) }\end{array}$ \\
\hline Sex & Binary & Male, female (in Haiti only, since all CHW respondents in Bangladesh and Kenya were female) \\
\hline Parity & Continuous & Number of children who live and do not live with the respondent (data available in Bangladesh only) \\
\hline \multicolumn{3}{|c|}{ Convergent validity measures: } \\
\hline $\begin{array}{l}\text { Number of } \mathrm{CHW} \\
\text { interactions }\end{array}$ & Categorical & $\begin{array}{l}\text { Three categories including one time, two to three times, four or more times. In Haiti, number of CHW interactions } \\
\text { in last six months. In Bangladesh, in last six months; note that for those who said } 0 \text { times }(\mathrm{n}=367) \text {, it is assumed } \\
\text { they saw a FWV, a facility-linked community health provider, and thus were included in the analysis, since question- } \\
\text { naire was a CHW exit interview. In Kenya half the sample is from ANC: "How many visits/contacts have you had with } \\
\text { CHWs in the last three months?" and half the sample from PNC: "How many times have you been in contact with a } \\
\text { CHW since childbirth?" }\end{array}$ \\
\hline Civic engagement & Continuous & $\begin{array}{l}\text { Mean score on seven-item Civic Engagement Scale, with items such as "I like to work on solving a problem in my com- } \\
\text { munity rather than waiting for someone else to address it." Four response options on Likert scale, 'strongly disagree', } \\
\text { 'disagree', 'agree', 'strongly agree', ranging from 1-4. Items were adapted from Peterson et al's sociopolitical control } \\
\text { scale [9]. We conducted split sample EFA/CFA. EFA results confirmed that civic engagement is a unidimensional con- } \\
\text { struct. CFA fit statistics were good and Cronbach's alpha and ordinal theta were } 0.89 \text { or higher for all three countries. }\end{array}$ \\
\hline Trust in CHWs & Continuous & $\begin{array}{l}\text { Mean score on 10-item Trust in CHWs Scale, ranging from 1-4. Limited to those who had contact with a communi- } \\
\text { ty-based CHW in the last six months (excludes } n=367 \text { in Bangladesh who saw FWVs). Details on the development } \\
\text { and validity of the Trust in CHWs Scale are documented in Sripad et al [29]. }\end{array}$ \\
\hline
\end{tabular}


Table 1. Continued

\section{VARIABLE NAME VARIABLE TYPE DEFINITION}

Mean score on five-item scale assessing CHW influence on various aspects of client empowerment in Bangladesh and Kenya, with the following items:

- I can better make decisions about my health and my children's health because of my interactions with CHWs.

- I can better share health information with others because of my interactions with CHWs.

- I can better get the care I need from my clinic because of my interactions with CHWs.

- I can better improve my clinic and/or the health system because of my interactions with CHWs.

Influence of

CHWs on

empowerment
Continuous

- I can better contribute to my community because of my interactions with CHWs.

There were four response options on a Likert scale, 'strongly disagree', 'disagree', 'agree', and 'strongly agree', with mean range from 1-4. The research team developed the items in this scale to explicitly assess CHW influence on empowerment. We conducted split sample EFA/CFA. EFA results confirmed that influence of CHWs on empowerment is a unidimensional construct; CFA statistics were good and alpha and ordinal theta were 0.75 and higher, suggesting good reliability. Further, we found that increasing $\mathrm{CHW}$ visits was significantly associated with increasing influence of CHWs on empowerment scores.

In Haiti, a similar 2-item index was used, for example "Do your interactions with your CHW improve your ability to make decisions about your health?" Response options were binary yes/no, with mean range from 0 to 1 .

Satisfied with Binary CHW services Responded 'very satisfied' to "At your most recent visit with the CHW, how satisfied were you with the services you received from the CHW?" vs all other responses ('very dissatisfied', 'somewhat dissatisfied', 'somewhat satisfied')

$\overline{\mathrm{CHW}}$ - community health worker, EFA/CFA - exploratory factor analysis/confirmatory factor analysis, FWV - family welfare visitor, ANC - antenatal care, PNC - postnatal care

*Also used for convergent validity.

\section{RESULTS}

A total of 2306 community members were included in analyses in Bangladesh ( $n=1384)$, Haiti $(n=616)$ and Kenya $(n=306)$. Less than $1 \%$ of prospective participants refused to participate. Table 2 describes sociodemographic characteristics by country. All participants in Bangladesh and Kenya were female; $85 \%$ were female in Haiti. Mean age in Bangladesh and Kenya was around 25 years and in Haiti, 40 years. Education levels varied by country, with low proportions of those with no education in Bangladesh and Kenya $(<10 \%)$ and $58 \%$ with no education in Haiti. The number of CHW interactions varied by country. The proportion of participants reporting four or more visits was 15\%,63\%, and 19\% in Bangladesh, Haiti, and Kenya, respectively.

Table 2. Sample sociodemographic characteristics by country

\begin{tabular}{|c|c|c|c|}
\hline & $\begin{array}{l}\text { BANGLADESH } \\
(\mathrm{N}=1384)\end{array}$ & $\begin{array}{c}\text { HAITI } \\
(N=616)\end{array}$ & $\begin{array}{c}\text { KENYA } \\
(\mathrm{N}=306)\end{array}$ \\
\hline & n (\%) & n (\%) & n (\%) \\
\hline \multicolumn{4}{|l|}{ Sex: } \\
\hline Female & $1384(100.0)$ & $524(85.1)$ & $306(100.0)$ \\
\hline Male & $0(0.0)$ & $92(14.9)$ & $0(0.0)$ \\
\hline $\begin{array}{l}\text { Age (mean, standard } \\
\text { deviation) (range) }\end{array}$ & $\begin{array}{c}24.3 \pm 5.1 \\
(15-35)\end{array}$ & $\begin{array}{c}40.0 \pm 17.6 \\
(15-90)\end{array}$ & $\begin{array}{c}26.5 \pm 6.1 \\
(16-45)\end{array}$ \\
\hline \multicolumn{4}{|l|}{ Education: } \\
\hline None & $75(5.4)$ & $359(58.3)$ & $25(8.2)$ \\
\hline Primary & $439(31.7)$ & $157(25.5)$ & $163(53.3)$ \\
\hline Secondary and above & $870(62.9)$ & $100(16.2)$ & $118(38.6)$ \\
\hline $\begin{array}{l}\text { Parity (mean, standard } \\
\text { deviation) (range) }\end{array}$ & $1.7 \pm 0.8(0-5)$ & $\mathrm{n} / \mathrm{a}$ & $\mathrm{n} / \mathrm{a}$ \\
\hline
\end{tabular}

For the split-sample EFA in Bangladesh ( $\mathrm{n}=692)$, Haiti $(\mathrm{n}=308)$, and Kenya ( $\mathrm{n}=153)$, PCA, scree plot, and parallel analysis suggested 2-3 factors for all three countries. Responses were not normally distributed for all items, thus we used iterative principal factor specification. Further, we used promax rotation as factors were correlated. We removed three items based on EFA results: one item had high uniqueness (0.8) and two items did not load greater than 0.3 on any factor. The item with high uniqueness was: "I feel confident that I will be seen by a health provider at a facility". This item was also deemed as not conceptually aligned with empowerment, and as likely depending more on facility capacity. The two items that did not load on any factor were: "I understand the important health issues that affect my community" and "I feel confident that I can ask

questions to health providers at facilities"; it is possible respondents may feel the latter item is not relevant to them if in fact they did not have questions.

The EFA suggested a three-factor solution of 16 items total: 7 items representing Personal agency around health, 4 items representing Agency in sharing health information with others, and 5 items representing Engagement in community health systems. Table 3 includes disaggregation of responses for each item in the resulting empowerment scale. Responses tended to skew towards 'agree' and 'strongly agree' for the 7-item Personal agency around health sub-scale, particularly in Bangladesh and Kenya. The 4-item Agency in sharing-health information sub-scale had more variation in item responses in all three countries compared to the Personal agency around health sub-scale. For the 5-item Engagement in community health systems sub-scale, in Bangladesh item responses skewed towards 'strongly disagree' and 'disagree', while responses were more varied in Haiti and Kenya. All factor loadings for the sub-scales and full-scale were significant $(P<0.001)$ and were greater than 0.3 in CFA (Table 3). 


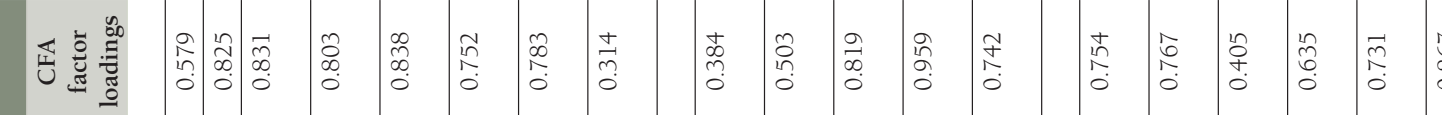

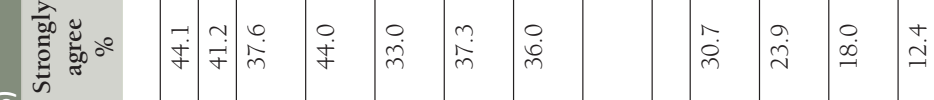
密

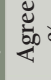

烈。

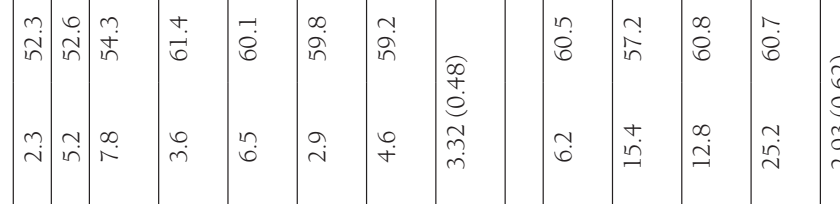

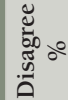

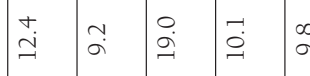

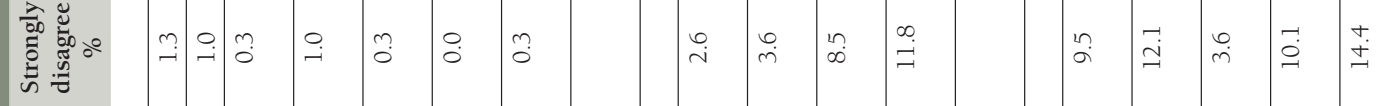

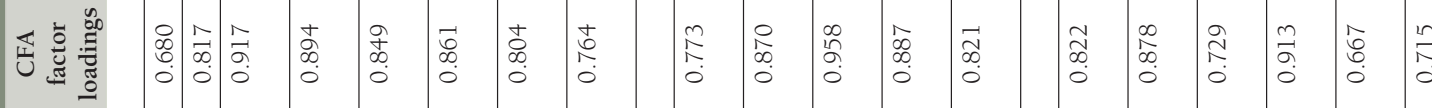

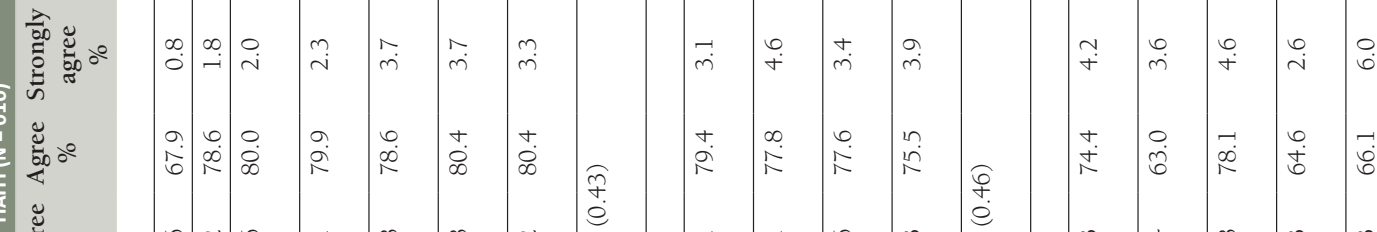

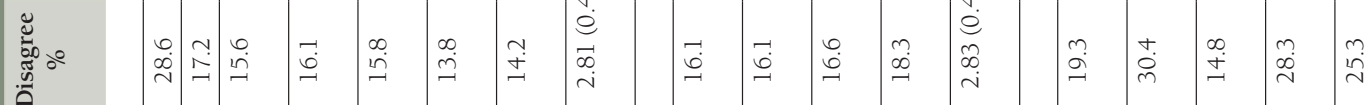

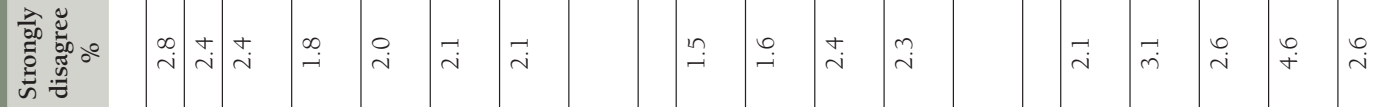

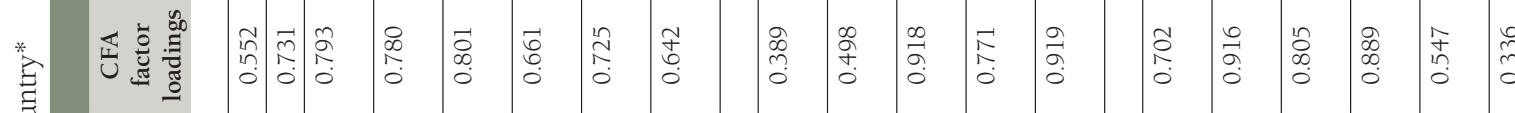

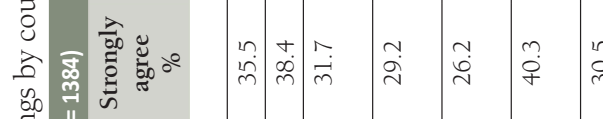

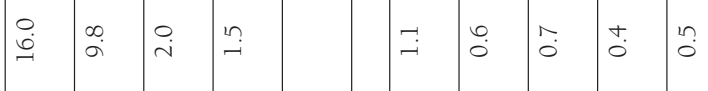

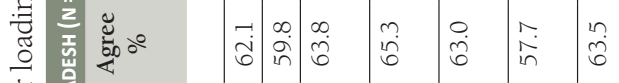

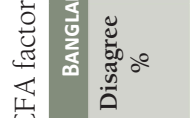

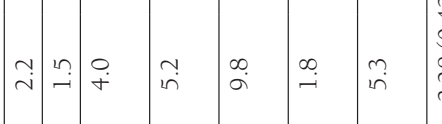

马) $\sqrt{1}$

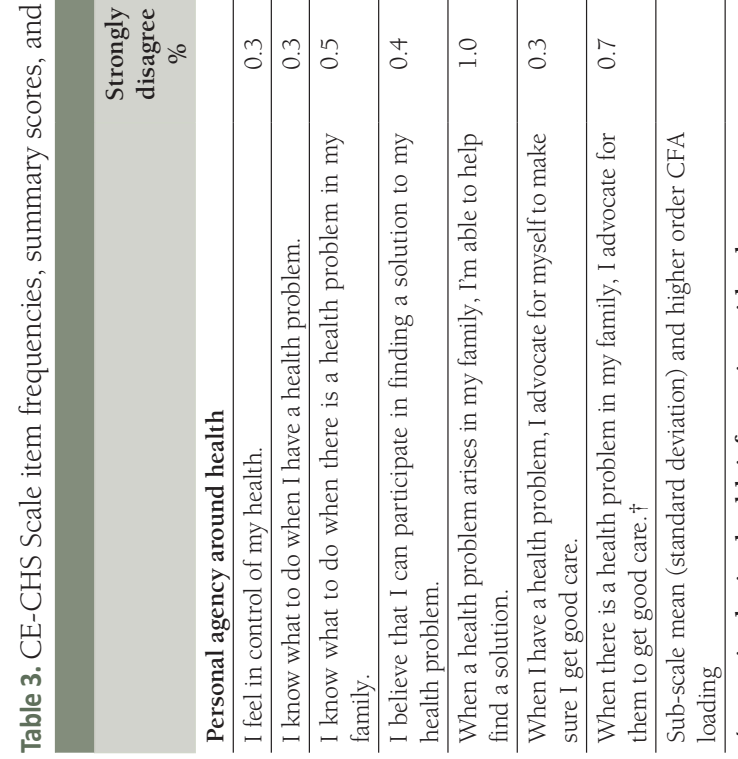

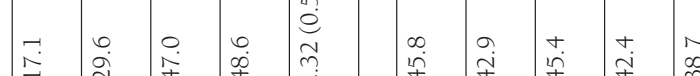


Table 4. Confirmatory factor analysis fit statistics by country*

\begin{tabular}{|c|c|c|c|}
\hline & BANGLADESH & HAITI & KENYA \\
\hline \multicolumn{4}{|c|}{ CE-CHS Scale: } \\
\hline RMSEA & 0.048 & 0.063 & 0.016 \\
\hline CFI & 0.979 & 0.971 & 0.998 \\
\hline TLI & 0.969 & 0.954 & 0.997 \\
\hline SRMR & 0.038 & 0.048 & 0.069 \\
\hline \multicolumn{4}{|c|}{ Sub-scales: } \\
\hline \multicolumn{4}{|c|}{ Personal agency around health (7 items): } \\
\hline RMSEA & 0.085 & 0.089 & 0.071 \\
\hline CFI & 0.986 & 0.990 & 0.987 \\
\hline TLI & 0.958 & 0.976 & 0.977 \\
\hline SRMR & 0.025 & 0.024 & 0.035 \\
\hline \multicolumn{4}{|c|}{ Agency in sharing health information with others ( 4 items): } \\
\hline RMSEA & 0.083 & 0.043 & 0.287 \\
\hline CFI & 0.995 & 1.000 & 0.956 \\
\hline TLI & 0.973 & 0.997 & 0.739 \\
\hline SRMR & 0.013 & 0.005 & 0.033 \\
\hline \multicolumn{4}{|c|}{ Engagement in community health systems ( 5 items): } \\
\hline RMSEA & 0.056 & 0.057 & 0.092 \\
\hline CFI & 0.999 & 0.996 & 0.971 \\
\hline TLI & 0.990 & 0.989 & 0.941 \\
\hline SRMR & 0.008 & 0.016 & 0.037 \\
\hline
\end{tabular}

CE-CHS - Client Empowerment in Community Health Systems, RMSEA - root mean square error of approximation, CFI - comparative fit index, TLI - Tucker-Lewis index, SRMR - standardized root mean square residual

*Number of correlated errors: Full scale (Bangladesh: 8; Haiti: 17; Kenya: 18), Personal agency around health sub-scale (Bangladesh: 8; Haiti: 5; Kenya: 2); Agency in sharing health information with others subscale (Bangladesh: 1; Haiti: 1; Kenya: 1); Engagement in community health systems sub-scale (Bangladesh: 3; Haiti: 0; Kenya: 0).
After adding modification indices, goodness of fit statistics across the structural equation models were acceptable, with RMSEAs less than 0.1 (in some cases, less than 0.05), CFIs and TLIs were greater than 0.9 (in some cases greater than 0.95), and SRMR less than 0.01 (and in some cases less than 0.05) (Table 4). In Kenya, the RMSEA and TLI for the Agency in sharing health information with others sub-scale did not meet cutoff criteria (at 0.287 and 0.739 , respectively). Higher-order CFA fit statistics were all significant, and sub-scale factor loadings on the higher-order factor were above 0.3 in Bangladesh and Kenya and 0.7 in Haiti (Table 3).

Internal consistency reliability for the full scale and each sub-scale, assessed using Cronbach's alpha and ordinal theta, were all at least adequate, at $>0.7$, and most above 0.8 or 0.9 (Table 5).

Mean CE-CHS score (range 1 to 4) was 2.38 in in Bangladesh, 2.79 in Haiti, and 3.0 in Kenya (Table 2). Mean Personal agency around health sub-scale score was 3.28, 2.81, and 3.32 in Bangladesh, Haiti, and Kenya, respectively. Mean Agency in sharing health-information was 2.32, 2.83, and 2.93 in Bangladesh, Haiti, and Kenya, respectively. Mean Engagement in community health systems was 1.54, 2.75, and 2.75 in Bangladesh, Haiti, and Kenya, respectively.

Descriptive statistics for the variables used to assess convergent validity are presented in Table 6. Mean civic engagement on a scale of 1 to 4 was 1.53 in Bangladesh and 2.66 in Haiti and Kenya. Mean influence of CHWs on empowerment on a scale of 1 to 4 in Bangladesh and Kenya was 2.18 and 3.18, respectively. Mean influence of CHWs on empowerment on a scale of 0 to 1 in Haiti was 0.91 . Satisfaction with CHW services varied by country: $29 \%$, $47 \%$, and $93 \%$ were very satisfied in Bangladesh, Kenya, and Haiti, respectively.

Table 5. Reliability of CE-CHS Scale and sub-scales

\begin{tabular}{|c|c|c|c|c|c|c|}
\hline & \multicolumn{2}{|c|}{ BANGLADESH $(\mathrm{N}=1384)$} & \multicolumn{2}{|c|}{ HAITI $(N=616)$} & \multicolumn{2}{|c|}{ KENYA $(\mathrm{N}=306)$} \\
\hline & Alpha & $\begin{array}{c}\text { Ordinal } \\
\text { theta }\end{array}$ & Alpha & $\begin{array}{c}\text { Ordinal } \\
\text { theta }\end{array}$ & Alpha & $\begin{array}{c}\text { Ordinal } \\
\text { theta }\end{array}$ \\
\hline CE-CHS Scale (16 items) & 0.860 & 0.900 & 0.912 & 0.967 & 0.856 & 0.915 \\
\hline \multicolumn{7}{|l|}{ Sub-scales: } \\
\hline Personal agency around health ( 7 items) & 0.885 & 0.930 & 0.941 & 0.970 & 0.913 & 0.954 \\
\hline Agency in sharing health information with others (4 items) & 0.758 & 0.811 & 0.930 & 0.948 & 0.821 & 0.865 \\
\hline Engagement in community health systems ( 5 items) & 0.888 & 0.929 & 0.829 & 0.925 & 0.732 & 0.771 \\
\hline
\end{tabular}

CE-CHS - Client Empowerment in Community Health Systems

Table 6. Frequencies of convergent validity items by country

\begin{tabular}{|c|c|c|c|}
\hline & BANGLADESH ( $\mathrm{N}=1384)$ & HAITI $(N=616)$ & KENYA (N = 306) \\
\hline & $\mathrm{n}(\%)$ & n (\%) & n (\%) \\
\hline \multicolumn{4}{|l|}{ Number of CHW interactions:* } \\
\hline 1 time & $595(43.0)$ & $68(11.0)$ & $91(30.7)$ \\
\hline $2-3$ times & $577(41.7)$ & $159(25.8)$ & $147(49.7)$ \\
\hline $4+$ times & $212(15.3)$ & $389(63.2)$ & $58(19.6)$ \\
\hline Civic engagement (range: 1-4) (mean, standard deviation) & $1.51 \pm 0.53$ & $2.66 \pm 0.51$ & $2.64 \pm 0.68$ \\
\hline Trust in CHWs (range: 1-4) (mean, standard deviation) $\dagger$ & $3.49 \pm 0.45$ & $3.79 \pm 0.43$ & $3.39 \pm 0.65$ \\
\hline Influence of CHWs on empowerment (mean, standard deviation)丰 & $2.18 \pm 0.55$ & $0.91 \pm 0.25$ & $3.18 \pm 0.58$ \\
\hline Satisfied with CHW services & $403(29.1)$ & $572(92.9)$ & $144(47.1)$ \\
\hline \multicolumn{4}{|c|}{$\begin{array}{l}\text { CHW - community health worker } \\
\text { * Missing } 10 \text { observations in Kenya. } \\
\text { †Limited to only those who had contact with a CHW in the last } 6 \text { months, since Trust in CHWs Scale specifically related to a CHW visit } \\
\text { in the last } 6 \text { months; Bangladesh, } \mathrm{n}=1017 \text {. }\end{array}$} \\
\hline
\end{tabular}




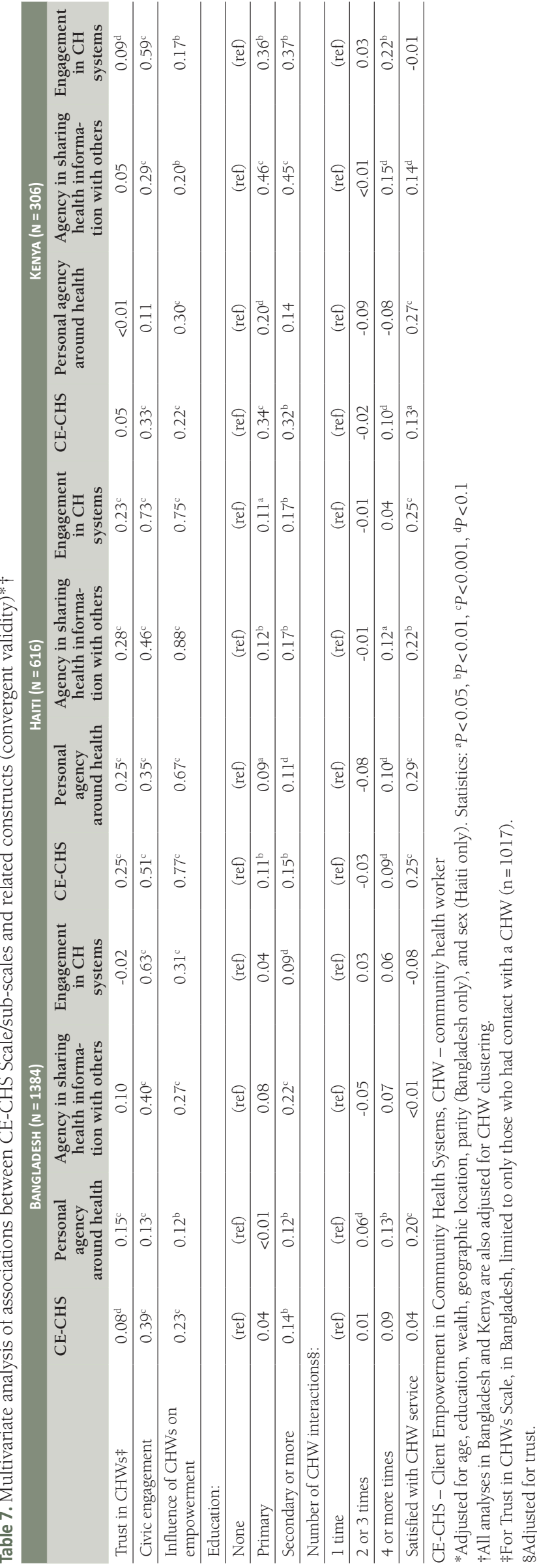

In multivariate analyses adjusting for age, education, wealth, geographic location, parity (Bangladesh only), sex (Haiti only), and CHW clustering (Bangladesh and Kenya only), higher empowerment scores were consistently associated with higher levels of each of these related constructs, as hypothesized, although the magnitudes of associations varied (Table 7). Similar associations were seen for both the full CE-CHS and each of the sub-scales.

Increased trust in CHWs was significantly associated with greater client empowerment in Haiti for the CE-CHS Scale and each of the sub-scales (all $P<0.001$ ), and in Bangladesh for the CE-CHS $(P<0.1)$ and Personal agency around health sub-scale $(P<0.001)$. Civic Engagement was associated with greater empowerment in all three countries (all $P<0.001$, except Personal agency around health in Kenya, which was non-significant). Increased perceived influence of CHWs on empowerment was significantly associated with higher empowerment in all three countries (most $P<0.001$ ). Those with secondary education or higher had significantly higher empowerment than those who had no education in all three countries, albeit with varying levels of significance for subscales. Having more CHW interactions was also significantly associated with greater empowerment in all three countries with varying levels of significance. Finally, satisfaction with CHW services was significantly associated with greater empowerment in all three countries, although not for all sub-dimensions in Bangladesh and Kenya, nor for the full scale in Bangladesh.

While the scale performed well overall, we recommend minor changes to how three questions are phrased in future scale implementations, to further strengthen the scale. Study team members from all three countries reviewed these changes to ensure face validity. We recommend that the item "I feel confident sharing health information with my family/friends in one-on-one conversations" be changed to "I feel confident sharing about my health experiences with my family/friends." Additionally, we recommend that the item "I feel confident sharing health information with my family/friends when we are in a group," be changed to "I feel confident sharing health information with my family/friends." These changes help further emphasize that the first item is about sharing personal experiences with clients' own experiences of health care, while the second item is about sharing health information or knowledge more broadly with their community including family and friends. Additionally, we recommend changing the item "I can participate in making decisions for my community" to "I can participate in making decisions that can improve health in my community," so that the item more explicitly relates to decisions around community health. Box 1 includes the final recommended scale items and scoring for the CE-CHS.

\section{DISCUSSION}

The 16-item CE-CHS Scale which contains three sub-scales - Personal agency around health (individual-level), Agency in sharing health information with others (interpersonal-level), and 
Now I will read a series of statements. Please let me know how much you agree or disagree with each of these statements by responding that you 'strongly disagree', 'disagree', 'agree', or 'strongly agree'.

Personal agency around health

1. I feel in control of my health.

2. I know what to do when I have a health problem.

3. I know what to do when there is a health problem in my family.

4. I believe that I can participate in finding a solution to my health problem.

5. When a health problem arises in my family, I am able to help find a solution.

6. When I have a health problem, I advocate for myself to make sure I get good care.

7. When there is a health problem in my family, I advocate for them to get good care.

Agency in sharing health information with others

8. I feel confident sharing about my health experiences with my family/friends.

9. I feel confident sharing health information with my family/friends.

10. I feel confident sharing health information with others in my community in one-on-one conversations. 11. I feel confident sharing health information with others in my community when in group/public settings. Engagement with community health systems

12. There are ways for me to participate in sharing my concerns/giving feedback to providers/managers at health facilities.

13. There are ways for me to participate in sharing my concerns/giving feedback to local leaders in my community.

14. Most facility providers/managers would listen to any concerns I raise.

15. Most local leaders in my community would listen to any concerns I raise.

16. I can participate in making decisions that can improve health in my community.

Scoring the Client Empowerment in Community Health Systems (CE-CHS):

Responses are scored as follows: 1 (strongly disagree), 2 (disagree), 3 (agree), 4 (strongly agree).

Generate mean sub-scale and full-scale scores by taking the mean of non-missing items for a final range of 1 to 4 .

Engagement in community health systems (community-level) - is the first multidimensional scale that measures empowerment specifically in the context of community health. We found strong support for the scale's validity and reliability across three unique settings. Empowerment, a key process and outcome itself, is recognized as a critical component to institutionalizing community health [12,30,31]. The 16-item CE-CHS Scale or any of its sub-scales, can be used by program managers and governments to measure changes in dimensions of client empowerment over time, including in response to interventions or policy changes.

Consistent with the literature, EFA/CFA confirmed that client empowerment is a multidimensional construct and should be measured as such $[32,33]$. There were notable differences in levels of the empowerment sub-dimensions by country, which highlights the role of the macrosystem in shaping empowerment. For example, there were lower levels of individual empowerment in Haiti - possibly attributed to prevailing insecurity and bursts of political instability, and slightly higher levels of individual empowerment in Bangladesh and Kenya [34]. There were lower levels of interpersonal and community empowerment in Bangladesh compared to in Kenya and Haiti. It is possible that interpersonal and community empowerment in the context of a family planning-focused survey in Bangladesh is inherently different than in the contexts of general health and maternal and child health in Haiti and Kenya. In Bangladesh, there is not one cohesive community health system, perhaps making interpersonal and community empowerment - for example advocacy within this system - more difficult. Overall, macrosystem factors such as a country's economic development status, political climate, and access to technology may contribute to differing levels of empowerment at the individual, interpersonal, and community levels. These differences underline the importance of measuring these various levels of empowerment that align with the socioecological model, to better understand which dimensions can be strengthened through programs.

Convergent validity results were quite consistent across the three countries for both the full-scale and subscales, suggesting that the three dimensions measured are important components of client empowerment in various settings. Results from this study align with prior literature suggesting that completing more education is associated with greater agency and empowerment [35]. We found that (controlling for trust in CHWs) more $\mathrm{CHW}$ interactions was associated with increased empowerment, suggesting that $\mathrm{CHW}$ programs are operating as intended - to build relationships and empower communities to enable better health and well-being. Further, we found that service satisfaction was associated with the full CE-CHS scale in Haiti and Kenya, and with the Personal agency around health sub-scale in all three countries. 
Notably, in Bangladesh and Haiti, client empowerment was associated with trust in CHWs - a scale also developed under the Frontline Health project [29]. Trust in CHWs and client empowerment are inextricably linked and should be measured together, since both are essential for effective community health systems [36-39]. In Kenya, further research with a larger sample size may be needed to elucidate the relationship between these two constructs. Additionally, across all three contexts, positive associations between client empowerment and civic engagement more broadly suggests utility in jointly applying these measures to assess valuable non-health outcomes of community health systems and CHW performance in particular [40].

While not the focus of this paper, it is important to highlight the new, unidimensional 5-item Influence of CHWs on Empowerment Scale. This scale directly and concisely assesses clients' perceived effect of CHWs on five health-related empowerment behaviors, which align with the personal, interpersonal, and community empowerment sub-dimensions of the CE-CHS Scale. This shorter scale could be included alongside the CE-CHS or given its brevity, could be used on its own to monitor quality improvement of CHW programs and accountability mechanisms for community health (eg, through national surveys and research studies). Implementing both scales together would be valuable for understanding client empowerment not directly related to CHWs, as in the CE-CHS, and for understanding more directly the effect of CHWs on empowerment, as in the Influence of CHWs on Empowerment Scale. Further, implementing these scales in combination with other metrics such as the Multi-dimensional Motivation Scale (also developed under the Frontline Health project), can contribute to measuring progress towards recommendations outlined in the World Health Organization's CHW Guidelines, the Community Health Roadmap, the Community Health Worker Assessment and Improvement Matrix (CHW AIM) toolkit, and the Minimum Quality Standards and Indicators for Community Engagement [41-45].

This study has several limitations. First, we could not assess predictive validity, as is ideal for scale validation, since we did not have longitudinal data nor enough suitable outcome variables (eg, clients' health outcomes/ service uptake) [19]. We suggest that future studies seek to establish predictive validity of this scale in relation to specific health outcomes of interest. Second, there was some lack of variation in item response frequencies, especially in Haiti. While this is a common phenomenon, and not overly concerning from a psychometric perspective, it still would be preferable to have greater variation across response options [19]. It may be that future implementation will capture such diversity in other contexts. Third, we did not have sufficient statistical power to test for scale invariance by potential subgroup differences. Fourth, non-random sampling approaches were used in Bangladesh and Kenya, thus potentially introducing selection bias to our results. Finally, findings may not be generalizable to other locations within the countries included in this study, other countries, other populations (eg, men), or other community health areas (eg, infectious diseases). These all are rich areas for future research.

\section{CONCLUSIONS}

Findings suggest that the CE-CHS Scale is valid and reliable in varying geographies. The CE-CHS Scale along with the Influence of CHWs on Empowerment Scale and Trust in CHWs Scale can be used in the context of implementation research and interventions focused on building empowerment and trust, such as community women's groups, community score cards, and community dialogue to build social accountability $[7,29,46,47]$. We hope researchers and program staff alike will find the CE-CHS Scale useful in assessing client empowerment in the context of community health systems worldwide.

Acknowledgements: The authors are deeply appreciative of the study participants for their time and participation. The authors would like to acknowledge those who supported field data collection and management including Md. Irfan Hossain and Shongkour Roy in Bangladesh, Maurice Junior Chery and Peterson Abnis Faure I in Haiti, and Daniel Mwanga in Kenya. We appreciate Dr Md. Moinuddin Ahmed and Nahid Sultana from the Directorate General of Family Planning of the Bangladesh Ministry of Health and Family Welfare, Community Focal Persons Catherine Munywoki and John Papai in Kilifi and Bungoma counties in Kenya, and Madame Guerline Bayas of the Ministère de la Santé Publique et de la Population in Haiti, for extending their support for conducting this study. Finally, the authors acknowledge Charlotte Warren and Ben Bellows for their feedback that strengthened this manuscript, and Sarah Kennedy for her excellent coordination support.

Ethics: Ethical approval was obtained from the Population Council Institutional Review Board in New York, USA (p874, p879, and p876), as well as the Bangladesh Medical Research Council (20608052019), the Zanmi Lasante Institutional Review Board in Haiti (ZLIRB2732019), and AMREF Health Africa Ethics and Social Review Committee in Kenya (p573).
} 
Funding: This paper is based on research funded by the Bill \& Melinda Gates Foundation. The findings and conclusions contained within are those of the authors and do not necessarily reflect positions or policies of the Bill \& Melinda Gates Foundation.

Authorship contributions: TM led the analyses and wrote the manuscript. PS and AG conceptualized and designed the study, co-led the analysis, supported analytic decisions at each iteration of scale development and testing, and provided substantial feedback on multiple drafts of the manuscript. AC, SH, and TA led study implementation in Haiti, Bangladesh and Kenya, respectively, contributed to preliminary scale item decisions based on qualitative analyses and item generation, and reviewed the manuscript, providing key scale-contextualization inputs. All authors approved the manuscript.

Competing interests: The authors completed the ICMJE Unified Competing Interest form at (available upon request from the corresponding author), and declare no conflicts of interest.

1 Laverack G. Improving health outcomes through community empowerment: a review of the literature. J Health Popul Nutr. 2006;24:113-20. Medline:16796158

2 Agarwal S, Sripad P, Johnson C, Kirk K, Bellows B, Ana J, et al. A conceptual framework for measuring community health workforce performance within primary health care systems. Hum Resour Health. 2019;17:86. Medline:31747947 doi:10.1186/ s12960-019-0422-0

3 Laverack G, Wallerstein N. Measuring community empowerment: a fresh look at organizational domains. Health Promot Int. 2001;16:179-85. Medline:11356756 doi:10.1093/heapro/16.2.179

4 Jennings MC, Pradhan S, Schleiff M, Sacks E, Freeman PA, Gupta S, et al. Comprehensive review of the evidence regarding the effectiveness of community-based primary health care in improving maternal, neonatal and child health: 2 . maternal health findings. J Glob Health. 2017;7:1. Medline:28685040 doi:10.7189/jogh.07.010902

5 Seward N, Neuman M, Colbourn T, Osrin D, Lewycka S, Azad K, et al. Effects of women's groups practising participatory learning and action on preventive and care-seeking behaviours to reduce neonatal mortality: A meta-analysis of cluster-randomised trials. PLoS Med. 2017;14:12. Medline:29206833 doi:10.1371/journal.pmed.1002467

6 Manandhar DS, Osrin D, Shrestha BP, Mesko N, Morrison J, Tumbahangphe KM, et al. Effect of a participatory intervention with women's groups on birth outcomes in Nepal: cluster-randomised controlled trial. Lancet. 2004;364:970-9. Medline:15364188 doi:10.1016/S0140-6736(04)17021-9

7 Prost A, Colbourn T, Seward N, Azad K, Coomarasamy A, Copas A, et al. Women's groups practising participatory learning and action to improve maternal and newborn health in low-resource settings: a systematic review and meta-analysis. Lancet. 2013;381:1736-46. Medline:23683640 doi:10.1016/S0140-6736(13)60685-6

8 Bronfenbrenner U. The ecology of human development: Harvard university press; 1979.

9 Peterson NA, Peterson CH, Agre L, Christens BD, Morton CM. Measuring Youth Empowerment: Validation of a Sociopolitical Control Scale for Youth in an Urban Community Context. J Community Psychol. 2011;39:592-605. doi:10.1002/jcop.20456

10 Kok MC, Ormel H, Broerse JE, Kane S, Namakhoma I, Otiso L, et al. Optimising the benefits of community health workers' unique position between communities and the health sector: a comparative analysis of factors shaping relationships in four countries. Glob Public Health. 2017;12:1404-32. Medline:27133127 doi:10.1080/17441692.2016.1174722

11 Perry HB, Zulliger R, Rogers MM. Community health workers in low-, middle-, and high-income countries: an overview of their history, recent evolution, and current effectiveness. Annu Rev Public Health. 2014;35:399-421. Medline:24387091 doi:10.1146/annurev-publhealth-032013-182354

12 Pfaffmann Zambruni J, Rasanathan K, Hipgrave D, Miller NP, Momanyi M, Pearson L, et al. Community health systems: allowing community health workers to emerge from the shadows. Lancet Glob Health. 2017;5:e866. Medline:28807181 doi:10.1016/ S2214-109X(17)30268-1

13 Cyril S, Smith BJ, Renzaho AM. Systematic review of empowerment measures in health promotion. Health Promot Int. 2016;31:809-26. Medline:26137970

14 Peterson NA, Zimmerman MA. Beyond the individual: Toward a nomological network of organizational empowerment. Am J Community Psychol. 2004:34:129-45. Medline:15495799 doi:10.1023/B:AJCP.0000040151.77047.58

15 Zimmerman MA. Psychological empowerment: issues and illustrations. Am J Community Psychol. 1995;23:581-99. Medline:8851341 doi:10.1007/BF02506983

16 Fawcett SB, Paine-Andrews A, Francisco VT, Schultz JA, Richter KP, Lewis RK, et al. Using empowerment theory in collaborative partnerships for community health and development. Am J Community Psychol. 1995;23:677-97. Medline:8851345 doi:10.1007/BF02506987

17 Rappaport J. Terms of empowerment/exemplars of prevention: Toward a theory for community psychology. Am J Community Psychol. 1987;15:121-48. Medline:3604997 doi:10.1007/BF00919275

18 Frontline Health Project. 2020. Frontline Health: Harmonizing Metrics, Advancing Evidence, Accelerating Policy Project Overview Brief. Washington, D.C.: Population Council.

19 DeVellis RF. Scale Development Theory and Applications. Fourth ed: Sage Publications; 2016.

20 Hossain S, Sripad P, Zieman B, Roy S, Kennedy S, Hossain I, et al. Measuring quality of care at the community level using the contraceptive method information index plus and client reported experience metrics in Bangladesh. J Glob Health. 2021;11:07007. doi:10.7189/jogh.11.07007

21 Zieman B, Abuya T, Mwanga D, Wanyugu J, Warren CE, Sripad P. Community-based postnatal care services for women and newborns in Kenya: an opportunity to improve quality and access? J Glob Health. 2021;11:07006. doi:10.7189/jogh.11.07006 
22 Gottert A, Friedland B, Geibel S, Nyblade L, Baral S, Kentutsi S, et al. The People Living with HIV (PLHIV) Resilience Scale: development and validation in three countries in the context of the PLHIV Stigma Index. AIDS Behav. 2019;23:172-82. Medline:31350712 doi:10.1007/s10461-019-02594-6

23 Gottert A, Barrington C, Pettifor A, McNaughton-Reyes HL, Maman S, MacPhail C, et al. Measuring men's gender norms and gender role conflict/stress in a high HIV-prevalence South African setting. AIDS Behav. 2016;20:1785-95. Medline:27209467 doi:10.1007/s10461-016-1374-1

24 Ozawa S, Sripad P. How do you measure trust in the health system? A systematic review of the literature. Soc Sci Med. 2013;91:10-4. Medline:23849233 doi:10.1016/j.socscimed.2013.05.005

25 Bann CM, Sirois FM, Walsh EG. Provider Support in Complementary and Alternative Medicine: Exploring the Role of Patient Empowerment. J Altern Complement Med. 2010;16:745-52. Medline:20575703 doi:10.1089/acm.2009.0381

26 High-Impact Practices (HIPs) in Maternal and Newborn Health. Encouraging empowerment and self-care through participatory women's groups and group antenatal care: supporting women to be at the center of their own care as active participants. Washington, DC: Population Council; 2020. Available: https://www.popcouncil.org/research/ending-eclampsial. Accessed July 30, 2020.

27 Zumbo BD, Gadermann AM, Zeisser C. Ordinal versions of coefficients alpha and theta for Likert rating scales. J Mod Appl Stat Methods. 2007;6:21. doi:10.22237/jmasm/1177992180

28 Rutstein SO, Johnson K. The DHS Wealth Index. DHS Comparative Reports No. 6. Calverton, Maryland: ORC Macro; 2004.

29 Sripad P, McClair TL, Casseus A, Hossain S, Abuya T, Gottert A. Measuring client trust in community health workers: a multi-country validation study. J Glob Health. 2021;11:07009. doi:10.7189/jogh.11.07009

30 Cattaneo LB, Chapman AR. The process of empowerment: a model for use in research and practice. Am Psychol. 2010;65:646. Medline:20873882 doi:10.1037/a0018854

31 Kane S, Kok M, Ormel H, Otiso L, Sidat M, Namakhoma I, et al. Limits and opportunities to community health worker empowerment: a multi-country comparative study. Soc Sci Med. 2016;164:27-34. Medline:27459022 doi:10.1016/j. socscimed.2016.07.019

32 Christens BD. Toward relational empowerment. Am J Community Psychol. 2012;50:114-28. Medline:22094588 doi:10.1007/ s10464-011-9483-5

33 Spreitzer GM. Psychological empowerment in the workplace: Dimensions, measurement, and validation. Acad Manage J. 1995;38:1442-65.

34 Sripad P, Casseus A, Kennedy S, Benito I, Vissieres K, Warren C, et al. "Eternally restarting" or "a branch line of continuity": Exploring consequences of external shocks on community health systems in Haiti. J Glob Health. 2021;11:07004. doi:10.7189/ jogh.11.07004

35 Kabeer N. Resources, agency, achievements: Reflections on the measurement of women's empowerment. Dev Change. 1999;30:435-64. doi:10.1111/1467-7660.00125

36 Sripad P. Trust in maternity care: A contextual exploration of meaning and determinants in peri-urban Kenya (unpublished dissertation). Johns Hopkins University; 2015.

37 Becker J, Kovach AC, Gronseth DL. Individual empowerment: How community health workers operationalize self-determination, self-sufficiency, and decision-making abilities of low-income mothers. J Community Psychol. 2004;32:327-42. doi:10.1002/jcop. 20000

38 Nxumalo N, Goudge J, Manderson L. Community health workers, recipients' experiences and constraints to care in South Africa-a pathway to trust. AIDS Care. 2016;28:61-71. Medline:27345712 doi:10.1080/09540121.2016.1195484

39 Wesson DE, Lucey CR, Cooper LA. Building Trust in Health Systems to eliminate health disparities. JAMA. 2019;322:111-2. Medline:31173060 doi:10.1001/jama.2019.1924

40 Wiggins N, Johnson D, Avila M, Farquhar SA, Michael YL, Rios T, et al. Using popular education for community empowerment: perspectives of Community Health Workers in the Poder es Salud/Power for Health program. Crit Public Health. 2009;19:1122. doi:10.1080/09581590802375855

41 WHO guideline on health policy and system support to optimize community health worker programmes. Geneva: World Health Organization; 2018.

42 Community Health Roadmap. Investment priorities to scale primary care at the community level 2019. Available: https://www. communityhealthroadmap.org/. Accessed:17 July 2020.

43 UNICEF. Minimum Quality Standards and Indicators for Community Engagement. 2020.

44 Ballard M, Bonds M, Burey J, Dini H, Foth J, Furth R, et al. CHW AIM: Updated Program Functionality Matrix for Optimizing Community Health Programs. 2018.

45 Gottert A, McClair TL, Hossain S, Dakouo SP, Abuya T, Kirk K, et al. Development and validation of a multi-dimensional scale to assess community health worker motivation. J Glob Health. 2021;11:07008. doi:10.7189/jogh.11.07008

46 Mafuta EM, Dieleman MA, Essink L, Khomba PN, Zioko FM, Mambu TN, et al. Participatory approach to design social accountability interventions to improve maternal health services: a case study from the Democratic Republic of the Congo. Glob Health Res Policy. 2017;2:4. Medline:29202072 doi:10.1186/s41256-017-0024-0

47 Gullo S, Galavotti C, Sebert Kuhlmann A, Msiska T, Hastings P, Marti CN. Effects of a social accountability approach, CARE's Community Score Card, on reproductive health-related outcomes in Malawi: A cluster-randomized controlled evaluation. PLoS One. 2017;12:e0171316. Medline:28187159 doi:10.1371/journal.pone.0171316 